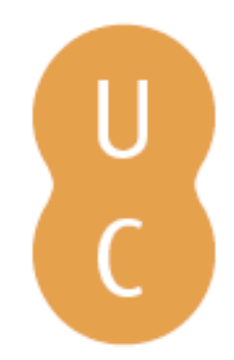

\title{
nombalina
}

\section{La pedagogía en y de la sociedad cognitiva}

\author{
Autor(es): V Vázquez Gómez, Gonzalo
}

Publicado por: Imprensa da Universidade de Coimbra

URL

persistente: URI:http://hdl.handle.net/10316.2/38388

DOI: $\quad$ DOI:http://dx.doi.org/10.14195/978-989-26-0486-2_10

Accessed : $\quad$ 26-Apr-2023 15:01:26

A navegação consulta e descarregamento dos títulos inseridos nas Bibliotecas Digitais UC Digitalis, UC Pombalina e UC Impactum, pressupõem a aceitação plena e sem reservas dos Termos e Condições de Uso destas Bibliotecas Digitais, disponíveis em https://digitalis.uc.pt/pt-pt/termos.

Conforme exposto nos referidos Termos e Condições de Uso, o descarregamento de títulos de acesso restrito requer uma licença válida de autorização devendo o utilizador aceder ao(s) documento(s) a partir de um endereço de IP da instituição detentora da supramencionada licença.

Ao utilizador é apenas permitido o descarregamento para uso pessoal, pelo que o emprego do(s) título(s) descarregado(s) para outro fim, designadamente comercial, carece de autorização do respetivo autor ou editor da obra.

Na medida em que todas as obras da UC Digitalis se encontram protegidas pelo Código do Direito de Autor e Direitos Conexos e demais legislação aplicável, toda a cópia, parcial ou total, deste documento, nos casos em que é legalmente admitida, deverá conter ou fazer-se acompanhar por este aviso.

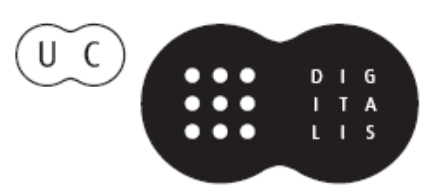


João Boavida

Ángel García del Dujo

Coordenação

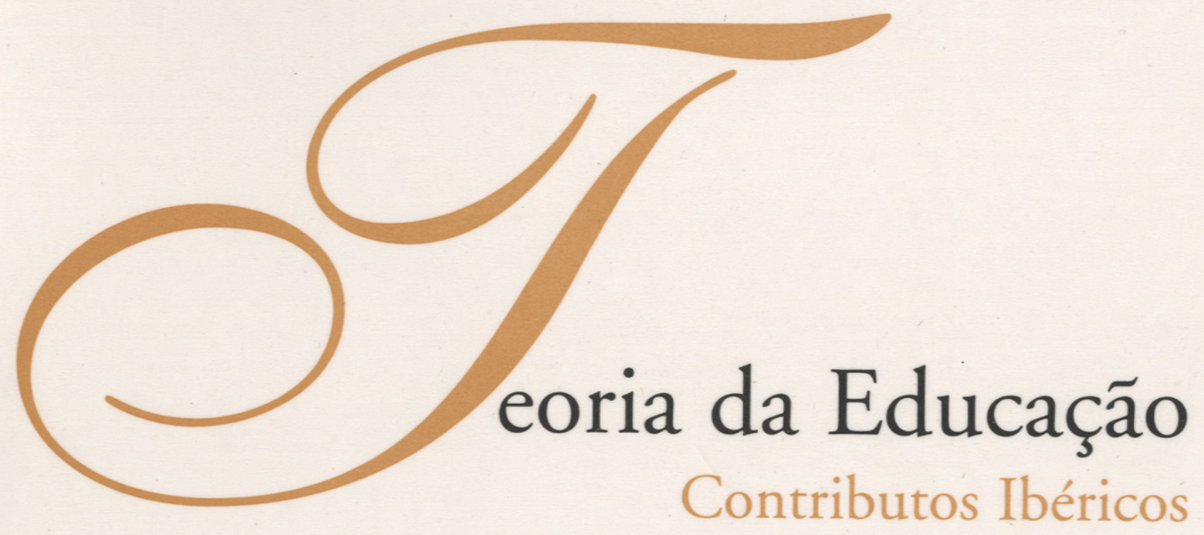


Gonzalo Vázquez Gómez

Universidad Complutense de Madrid

La Pedagogía en y de la Sociedad Cognitiva

\section{Pensar la educación. La elaboración del conocimiento en la sociedad de la información}

En 2006 se cumple medio siglo año del nacimiento de la ciencia cognitiva, del acontecimiento de «la ruptura cognitiva». La historia de la ciencia ha precisado más la fecha del nacimiento, el 11 de septiembre de 1956, en el segundo día del Symposium on Information Theory que tuvo lugar en el MIT®. En ese mismo año veían la luz algunos trabajos seminales para el desarrollo de las primeras ciencias cognitivas como la psicología y la lingüística@. Cuarenta años después habría de aparecer, en el marco de la Unión Europea, el Libro Blanco sobre la Educación y la Formación con el subtítulo de Enseñar y aprender. Hacia una sociedad cognitiva.

Podemos adoptar estas dos fechas (1956 y 1995) para caracterizar la segunda mitad del siglo XX como el tiempo de las ciencias y de las tecnologías cognitivas y de sus efectos sobre los sistemas educativos. En efecto, las leyes educativas promulgadas desde finales de los años ochenta

Miller, G. A. (1979). A very personal history.Talk to Cognitive Science Workshop. Cambridge, Mass, MIT. 1 June 1979. Gardner, H. (1985). The mind's new Science. A history of the cognitive revolution (chap. 3).

(B) Entre otros trabajos, aparecieron ese año: A study of thinking. (de Bruner, Goodnow y Austin), The magicai number seven, plus or minus two: some limits on our capacity for Processing information (artículo de Miller) y Three models on language (de Chomsky). 
hacen referencia continuada a las relaciones entre el sistema educativo y el desarrollo de la información haciendo descansar la ordenación del sistema sobre el principio del aprendizaje y de la formación a lo largo de toda la vida(3).

El problema básico con el que se encuentran hoy los sistemas educativos es el de la finalidad de la educación y de las instituciones educativas en la sociedad de la información. Este problema tiene que hacer pensar a la pedagogía y, dentro de ésta, a la teoría de la educación. En el proceso de constaicción de una pedagogía cognitiva no se pueden ignorar algunos de los principales problemas sobre el conocimiento. Entre ellos, se pueden identificar los siguientes: el de la contraposición entre «conocimiento» y «conocer», el de la persistencia 0 dilución del sujeto que conoce (y, en el caso de su existencia, quién es efectivamente ese sujeto que conoce(4), el de la consistencia y persistencia de lo conocido, el de su valor y, por último, de las vías para llegar al propio conocimiento.

Tanto si examinamos nuestro problema desde la perspectiva de la ciencia cognitiva como de la teoría del conocimiento, nos topamos con la dificultad de dar una respuesta única, general, a estas cuestiones. Desde aquélla, se reconoce una pluralidad de disciplinas preocupadas por ese objeto de estudio, de modo que se tiende a hablar, no de la ciencia cognitiva, sino de las ciencias (disciplinas y tecnologías) cognitivas. En términos filosóficos, la dificultad se formula en términos de una teoría (igeneral?) del conocimiento; y algo semejante sucede desde la perspectiva epistemológica. Hemos de admitir, pues, los obstáculos para conocer una sola y definitiva respuesta al

(3) Así ha ocurrido en los casos portugués y español; en el primero, con la Ley 46/86, de 14 de Octubre de 1986 modificada la Ley no 115/97, de 19 de Septiembre de 1997 (Ley de Bases del Sistema Educativo); en el segundo, con la Ley Orgánica 1/1990 de Ordenación General del Sistema Educativo (de 3 de octubre de 1990), la Ley Orgánica 10/2002 de Calidad de la Educación (23 de diciembre de 2002) y el actual Anteproyecto de Ley Orgánica de Educación.

(4) García del Dujo, A. (1992). Constructivismo e intervención pedagógica: a propósito de quién construye. Teoría de la Educación, IV, pp. 127-138; el autor concluye que hay múltiples «momentos» y «lugares» donde tienen lugar procesos constructivos y siempre más de un constructor (p. 137). 
problema del conocimiento: si el conocimiento no es completo, ni definitivo, tampoco el conocimiento sobre el mismo conocimiento.

Cuando se afronta la cuestión de la elaboración o construcción del conocimiento en la sociedad actual, se tiende a dar por supuesto que 10 que existe es la posibilidad de la experiencia del conocer, más que de la realidad del conocimiento. La filosofía clásica considera el conocimiento como el efecto de la adecuación entre el entendimiento del sujeto cognoscente y la realidad conocida. En la actualidad, nos vemos casi imposibilitados de formular la cuestión en estos términos dada «la enemiga que se ha declarado al sujeto con todas las teorías de la deconstrucción, que, básicamente, es deconstrucción del sujeto y, por tanto, del sujeto cognoscente» (Rábade, 1995)(5) a lo más que se podría llegar sería a hablar de la experiencia del conocer, lo que equivale a hablar de tantas «lecturas» de un «texto» como individuos que tienen experiencia de esa realidad.

Esta apelación a la experiencia tiene su última manifestación en la experiencia continua y provoca el desinterés por el rigor, consistencia, estabilidad y valor de lo conocido(6). Este problema tiene fuertes componentes psicológicos y tecnológicos. En un reciente trabajo sobre la construcción del conocimiento, consideran Scardamalia y Bereiter (2003) que no hay métodos bien probados para formar a la gente para ser buenos productores de conocimiento. A falta de una respuesta segura sólo cabría hacer uso de algunas soluciones provisionales: bien de la de educar basándonos en el conocimiento básico disponible, bien de la de procurar la formación en destrezas más 0 menos específicas, ya de la de adoptar el enfoque de la construcción social del conocimiento dentro de enfoques tales como las «comunidades de aprendizaje», el «aprendizaje basado en proyectos» 0 el «descubrimiento guiado». Los dos primeros enfoques entrañan, según estos autores, el riesgo de desplazar el conocimiento avanzado al ámbito de una educación terminal a la que

(5) Rábade, S. (1995). Teoría del conocimiento. Madrid: Akal, 13.

(6) Rodríguez Neira, T. (1999). La cultura contra la escuela. Barcelona: Ariel. 
llegan muy pocos, sea en la educación de postgrado, sea en el mundo del trabajo cualificado. Por el contrario, desde el tercer enfoque se considera el conocimiento como una producción y mejora continuas del capital de ideas en una comunidad, generadas dentro de un proceso continuo a lo largo de toda la vida, dentro y fuera de la educación formal.

Estos enfoques no tienen un carácter necesariamente antagónico, sino que pueden actuar de forma sinérgica y convergente. Situados en la perspectiva de la construcción social del conocimiento, como un modelo global, adquiere sentido que en los primeros estadios se emplee más el conocimiento básico, así como el aprendizaje basado en problemas y en proyectos adquiere su mayor eficacia en fases más avanzadas, como se está haciendo desde hace mucho tiempo en la educación secundaria superior, en la universitaria y en el ejercicio profesional.

En la actualidad es preciso, no sólo pensar la educación, sino repensar la pedagogía, lo que, lejos de ser «un lujo», resulta una necesidad en la sociedad cognitiva ${ }^{(7)}$. La preocupación por pensar la pedagogía se ha formulado en los términos de equé tipo de pedagogía requieren los tiempos actuales ${ }^{(8)}$. Esta pregunta tiene diversos significados. Primero, que cada sociedad implica un tipo de educación, instituye un tipo de escuela y alienta una forma de pensar la educación. Segundo, que el progreso de la ciencia produce cambios en la estructura del pensamiento. Tercero, que la nueva sociedad, y la evolución de la ciencia y de la tecnología como construcciones sociales, requiere una nueva pedagogía.

Aceptadas estas premisas, nada hay de extraño en admitir la crisis actual del sistema educativo y de la institución escolar. De tal manera se han complicado las relaciones dentro del sistema educativo, que se entiende que

(7) Cfr. Revue Française de Pédagogie, (1997) (120) Juillet, août, septembre, 1997 (monográfico sobre Penser la pédagogie).

(8) Vázquez, G. (1991). La pedagogía como ciencia cognitiva. Revista Española de Pedagogía, 49 (181), pp. 123-146 y Vázquez, G. y Bárcena, F. (1999). Pedagogía cognitiva: la educación y el estudio de la mente en la sociedad de la información. Teoría de la Educación. Educación y Cultura en la Sociedad de la Información, (1) http://www3.usal.es/ teoriaeducacion/ 
es necesario reconsiderar conceptos tales como inteligencia, información, aprendizaje, enseñanza, formación, tiempo y espacio educativos, etc. Para tratar de comprender tamaños cambios, la teoría de la educación ha asumido el enfoque propio de las ciencias cognitivas en torno a las teorías de la complejidad y a adoptar el estudio y el símil del cerebro humano como modelo explicativo, tanto de la construcción del conocimiento «objetivo», como de la construcción de ideales, tanto acerca de las acciones y procesos, como de los ideales sobre la educación (dando sentido y descubriendo el significado de aquéllos), en correspondencia con el programa de investigación de los estudios neurobiológicos(9)).

Del mismo modo que en estos estudios se distingue entre los procesos de recogida y elaboración de la información según hemisferios (izquierdo y derecho) y niveles (más o menos cortical), nuestro conocimiento sobre la educación y sobre el propio conocimiento educativo se ve obligado a estimar las dos lógicas del cerebro y la mente humanas, así como el conocimiento explícito (más cercano a la construcción social del conocimiento) y tácito e implícito del educando, del educador y del pedagogo experto. Esto rige tanto respecto del conocimiento ordinario, como del conocimiento científico, por ejemplo en el caso de la pedagogía de la ciencia, y específicamente en el conocimiento sobre la educación.

\section{Características y demandas de la educación en la sociedad actual. Formación de personas y sistemas competentes}

Uno de los antecedentes del enfoque cognitivo sobre la educación es el de la Teoría General de los Sistemas (TGS) y, más concretamente, el de la cibernética. Durante los años 30 y 40 del pasado siglo Wiener trabajó

(9) Zeki, S. (2004). Esplendores y miserias del cerebro. En F. Mora (Coord.), Esplendores y miserias del cerebro (cap. 1). Madrid: Fundación Santander Central Hispano. 
con servomecanismos, lo que le condujo a ocuparse de la naturaleza del refuerzo (feedback) y de los sistemas autocorrectores y autorreguladores, ya fueran mecánicos o humanos(10) Hacia final de siglo, la aplicación de la cibernética a la educación daba lugar al reconocimiento de la pedagogía cibernética en un sentido tal que, sin renunciar a los conceptos clave de información y control, permitía la interpretación de la educación en un sentido humanístico, es decir, reconociendo la posibilidad de explicar la educación en el sentido proyectivo, superador, abierto a la autoconciencia y a la autodeterminación(11).

Conforme, pues, con este enfoque cognitivo, la educación, como sistema, debe considerarse substantivamente como un sistema abierto. Este enfoque se reconoce tanto en las exposiciones de motivos de las leyes de educación como en los estudios comparados y de organismos internacionales (UNESCO, OCDE, etc.). Así, por ejemplo, las leyes orgánicas promulgadas en España desde 1990 han expresado la interdependencia de la educación y otros sistemas (cultural, tecnológico, etc.). Si, como se ha dicho anteriormente, cada época crea y necesita un tipo de escuela y de inteligencia, es preciso esclarecer cuáles son los propios de esta tercera revolución «industrial», de la revolución cognitiva. El propio Wiener, en su obra originalmente titulada The human use of human beings y que nos otros conocemos por su subtítulo (Cybernetics and Society), se pregunta por las relaciones entre el desarrollo de la máquina y su influencia en la sociedad en las dos primeras revoluciones(12).

El reloj y la máquina textil constituyen los dos modelos mecánicos que expresan, paradigmáticamente, los instrumentos propios de esas dos revoluciones. Precisión, ahorro en la transmisión de energía, incremento

(10)Gardner, H. (1987). The mind's new Science. N. York: Basic Books, pp. 19-20.

(11)cfr. Sanvisens, A. (1991). Concepción sistémico-cibernética de la educación. En J. L. Castillejo y otros Teoría de la Educación. Conceptos y propuestas. Murcia: Límites, p. 167.

(12) Wiener, N. (1969). Cibernética y sociedad, (cap. 9: «La primera y la segunda evolución industrial»). Buenos Aires: Edit. Sudamericana. 
del rendimiento y automatización progresiva, son algunos de los valores que acreditan la calidad de los procesos de medición y fabricación de estas revoluciones industriales. Además de otros cambios graduales de la primera a la segunda revolución, el cambio radical es el del tipo de energía utilizada para mover la maquinaria, energía mecánica en el primer caso y eléctrica en el segundo. Como se ha dicho, el verdadero cambio radical en las revoluciones industriales no se ha producido tanto desde la primera a la segunda (ambas se pueden caracterizar, en un cierto sentido, como energías «físicas» y más 0 menos limitadas) como desde ésta a la tercera, a la revolución de la información. La base de este gran cambio en los procesos productivos es un nuevo tipo de energía que podemos considerar inmaterial y prácticamente ilimitada. A diferencia de las anteriores, es más fácil de almacenar y de procesar. La distribución de la información puede verse obstaculizada por diversos factores políticos, sociales, económicos, tecnológicos y cognitivos(13).

Lógicamente, estos cambios se han proyectado en la educación y, sobre todo, en la organización de los espacios y tiempos y en los «depósitos» de información. Uno de los problemas actuales de la Escuela es el de encontrar su lugar adecuado en la Sociedad de la Información. No son pocos los autores que entienden que la Escuela, tal como la hemos entendido, está llamada a desaparecer. Así, Sáez Vacas (1987) estima que la institución escolar es una torpe introductora de tecnología y que, como señalara Skibbins, la Escuela se parece a un inmenso mecanismo de relojería(14). En la medida en la que, veinte años después de estos juicios, fueran así las cosas (y todavía la Escuela está preocupada por calendarios, horarios, densidad de los programas, etc.), cabría todavía hoy decir que esta institución responde a la lógica de la primera, 0 a lo sumo, de la segunda revolución

(13) Albar, E. y Quintanilla, M. A. (2002). Cultura tecnológica. Estudios de Ciencia, Tecnología y Sociedad. Barcelona. ICE de la UB - Hor sori.

(!4) sáez, F. (1987). Computadores personales. Hacia un mundo de máquinas informáticas. Madrid: Fundesco, p. 186 y siguientes. La obra, citada, es de Skibbins, G. J. (1981). Organizational evolution. A program for managing radical change. Seaside, CA.: Inter systems Publ. 
industrial. Basta escuchar las quejas de los profesores en los momentos de reforma 0 renovación educativa, cuando todos suelen reclamar un horario más extenso para su materia, para ser conscientes de la vigencia de esta vieja lógica escolar.

Tenemos, pues, que la educación, desde una perspectiva cibernética y preocupada por dar respuesta a los problemas de la Sociedad de la Información, debe abrirse a nuevos formas de considerar la inteligencia, el aprendizaje y el conocimiento y, por consiguiente, los papeles del educando y del educador y los modos de concebir los espacios y los tiempos educativos. En primer lugar, quizá, la Pedagogía cognitiva deba poner en cuestión las ideas preconcebidas sobre inteligencia y aptitud. Las prácticas escolares, docentes, diagnósticas y de asesoramiento, descansan en supuestos acerca de la inteligencia propias de una edad industrial, tal como ha denunciado Wirth(15) Late aqui el problema de si la racionalidad tecnológica presupuesta por la intencionalidad en un proceso de acción es compatible con la realización de resultados valiosos (¿impone la intención el control tecnológico de las acciones?) o si es necesaria otro tipo de racionalidad más sensible a las cuestiones de valor(16) Ya el mismo Wiener nos prevenía sobre que la nueva revolución industrial es un arma de doble filo, que se puede utilizar en beneficio de la humanidad (si «la usa inteligentemente») 0 para destruirla( $\left.{ }^{17}\right)$. Se apunta aquí a la comunicabilidad entre inteligencia y calidad ética de las decisiones tomadas desde y con ella.

En la actualidad los sistemas educativos desarrollan estrategias de convergencia hacia el logro de personas y comunidades competentes. Dentro

(15) wirth, A. G. (1991). Toward a post-industrial intelligence and democratical renewal. Educational Philosophy and Theory, 23 (2), 1-8.

(16) wirth, art.cit, p. 2; ver, también, Escámez, J. y Pérez, P. M. (1992). Planificación de programas en educación no formal. En J. Sarramona (Ed.), La educación no formal (cap. 3). Barcelona: Ceac; y Vázquez, G. (1993). Inteligencia, tecnología y escuela en la sociedad post-industrial. En R. 0., McClintock, M. J. Streibel,, y G. Vázquez (1993). Comunicación, tecnología y diseños de instrucción: la construcción del conocimiento escolar y el uso de los ordenadores (cap. 7). Madrid: MEC-CIDE.

(17) Wiener, op. cit., p. 151. 
de este enfoque, una teoría cognitiva de la educación ha de formularse esta pregunta: ¿Es sensible el enfoque actualmente dominante de la tecnología de las competencias en el sistema educativo a las exigencias de una inteligencia abierta y contingente con el mundo del valor? La respuesta a esta cuestión puede adquirir una orientación positiva o negativa según cual sea el sentido que se preste al propio y radical concepto de competencia y a la dimensión cognitiva de la competencia humana (y, en su espacio propio, de las organizaciones y de las comunidades).

Los más recientes trabajos sobre las competencias educativas nos permiten reconocer la relación de parentesco entre «competencia (educativa)» y "competitividad» ${ }^{(18)}$. Existe un contagio entre estos dos términos que supone la lógica de la supervivencia de los más aptos o competentes, lógica, es innecesario insistir en ello, poco coherente, no ya con el sentido propio de la educación (lograr la mayor excelencia posible en todas las personas), sino incluso tan sólo con el enfoque de la construcción social del conocimiento. Otra relación que podríamos calificar de infecto-contagiosa es la de la asimilación del concepto de competencia al de habilidad. El homo compětens es muy superior al mero homo dexter, al homo habilis. El tesauro del ERIC refiere así ambos descriptores ${ }^{(19)}$.

Competence: The individual's demonstrated capacity to perform, i.e., the possession of knowledge, skills, and personal characteristics needed to satisfy the special demands or requirements of a particular situation;

\footnotetext{
(18) Sarramona, J. (2004). Competencias básicas en la escolaridad obligatoria. Barcelona: Ceac.

(19) ERIC (2005). Thesaurus. Descriptors: Competence and Abilty. Recuperado, el 6 de junio de 2005, de la World Wide Web: http://www.eric.ed.gov/. En el ámbito del lenguaje empresarial se utiliza también el término "capability" para referirse a las competencias o capacidades en relación con las de otras empresas, pero en general se entiende que no hay una distinción formal, ni de contenido, entre competencias y ccapabilities»; así, cfr.: Grant, R. M. (2005). Contemporary strategy analysis. Concepts, techniques, applications. Oxford (UK): Blackwell Publ. (cap. 5, en el que el autor sigue, a este respecto, la conocida posición de Hamel y Prahalad en su tratamiento de las competencias nucleares, o core-competencies, de las organizaciones).
} 
Ability: The degree of actual power present in an organism or system to perform a given physical or mental act.

El examen de estos dos descriptores nos descubre tres características básicas: la proximidad a la ejecución (manifiesta), la respuesta a las demandas inmediatas y la atención a situaciones particulares; de las tres se deduce una cuarta: la segmentación y el carácter específico, cuando no hiperespecífico, de la mayor parte de las competencias. La primera de ellas nos devuelve al tratamiento que Scardamalia y Bereiter dan a la construcción def conocimiento. En el citado trabajo salen estos autores al paso de la confusión que se suele producir entre constructivismo y construcción del conocimiento. Para ellos, es preciso distinguir entre formas manifiestas y no manifiestas de conocimiento de forma que sólo estas últimas están abiertas a la consciencia de los principios subyacentes, a los procesos de establecimiento y ajuste de las metas, a la «teorización» progresiva y mejora de los supuestos teóricos, a la monitorización y a la evaluación del proceso de avance; existen, además, procesos «superficiales» (poco explícitos) y otros a mitad de camino entre lo consciente y explícito y lo implícito y apenas accesible a la conciencia (tal sería el caso del descubrimiento guiado).

Sin embargo, hay argumentos a favor del carácter más latente, potencial y global de las competencias, razones de significación etimológica, de carácter filosófico y conceptual y de naturaleza biopsicológica. En primer lugar, el homo compétens está mucho más próximo a al homo agens, entendiendo agente según la primera acepción del Diccionario de la Real Academia Española: «que obra 0 tiene virtud de obrar» (D.R.A.E., subrayado añadido). Conforme con esta acepción, agente no es sólo el que ejecuta visible 0 manifiestamente la acción (que realiza una actividad), sino también quien reflexiona, se propone intencionalmente una acción, la elabora (incluso implícita 0 inconscientemente), etc. ¿Está El Pensador, de Rodin, en una actitud activa, muestra una competencia reflexiva? 
Esta profundización sobre el carácter del «competente» como «agente» está respaldada por la reflexión filosófica. Arendt refleja esta posibilidad (todavía no inmediatamente social de la construcción del conocimiento) cuando recuerda las condiciones de la realización del trabajo en la primera Edad Moderna(20):

No fueron los observadores y espectadores de las plazas de mercado medievales (donde el artesano, en su aislamiento, estaba expuesto a la luz pública), sino sólo el auge de la esfera social (en la que los demás no se contentan con contemplar, juzgar y admirar, sino que desean que se les admita en la compañía del artesano y participar como iguales en el proceso de trabajo), lo que amenazó el «espléndido aislamiento» del trabajador y socavó finalmente las mismas nociones de competencia y excelencia. Este aislamiento es la necesaria condición de vida de toda maestría, que consiste en estar sola con la «idea», con la imagen mental de la cosa que va a ser.

La potencial fecundidad de la idea, de la imagen mental «de lo que va a ser», suelda el carácter integral del doble movimiento del agens y del faber. Quizá por esta vía se puedan aproximar la cognición y el pensamiento que, a juicio de la misma autora, no son una misma cosa pues, mientras que éste es el origen de las obras de arte y se manifiesta en la filosofía sin modificación alguna, aquélla actúa movida por consideraciones prácticas de modo que, una vez alcanzado el objetivo, ahí finaliza( ${ }^{21)}$.

Esta misma distinción, con posibilidad de integración, se reconoce en los estudios de la tecnología cognitiva sobre el proceso de llegar a ser experto, de la condición propia de la experticia. Se dice del experto que llega a dominar de tal modo sus propios procesos cognitivo-operativos que, con frecuencia, «ignora» (e incluso viola) los principios y reglas en los que real 0 supuestamente apoya 0 debería apoyar su práctica real. De ahí que

(20) Arendt, H. (1996). La condición humana. Barcelona: Paidós, 179.

(21) Arendt, op. cit., 187. 
se tiene como poco eficaz todo intento primerizo de imitar la práctica de un experto.

Cabe, también, argumentar sobre el carácter holístico, y no siempre patente y consciente, de las competencias desde una óptica biopsicológica. En efecto, es el organismo entero (el individuo o sujeto, la organización, la comunidad plena) quien es competente, generando e incluyendo entornos de competencia. Desde esta perspectiva, no cabe radicalmente hablar sino de la competencia humana como de la capacidad única para pensar sobre algo y ejecutar algo de una manera propia y excelente. La pedagogía cognitiva aboga a favor de la integración de las competencias en la competencia personal y rechaza, por estéril, el esfuerzo por segmentar las competencias hasta el punto de elaborar inventarios inacabables de competencias específicas ${ }^{(22)}$. Una consecuencia práctica de este enfoque se manifiesta en una preferencia lingüística: es más pertinente hablar de "dimensiones" (cognitivo-emocional, social, conductual,...) de las competencias que de «componentes» (cognitivos, emocionales, sociales, etc.) de ellas. Finalmente, si volvemos a considerar la relación de contagio entre competencia y competitividad, es oportuno pensar, con d'Iribarne, que la competencia humana es la base de la competitividad $^{(23)}$. Las modernas teorías del capital humano y de la gestión del conocimiento han de partir de estos supuestos básicos acerca del carácter integral, potencial y personal de las competencias.

Podemos, pues, concluir este punto afirmando que el proceso de formación de las competencias se enraíza en el proceso de formación humana, que se confunde con la educación general (en general), con la educación básica de la persona.

(22) Vázquez, G. (1999). A favor del carácter general de las competencias. Addenda a la ponencia de Sarramona, J. y Pintó, C. Identificación de las competencias básicas al término de la Educación Secundaria Obligatoria. XVIII Seminario Interuniversitario de Teoría de la Educación. Guadalupe (Cáceres): Universidad de Extremadura. Recuperado, el 7 de junio de 2005, de la World Wide Web: http://www.ucm.es/info/site/docu/18site/a4vazq.pdf.

(23) Iribarne, A. d' (1989). La compétitivité: Un défi social, un enjeu éducatif. Paris. C.N.R.S. 


\section{Algunos problemas de la pedagogía cognitiva (cognición, emoción, memoria y mente)}

La Pedagogía comparte con otras ciencias cognitivas su preocupación por el conocimiento. Nuestra disciplina no forma parte de las seis reconocidas por Gardner en 1985 (Filosofía, Psicología, Lingüística, Inteligencia Artificial, Antropología y Neurociencia), ni tan siquiera de otras disciplinas y tecnologías cognitivas que se le han sumado después (Economía, Sociología, Ciencia Política, etc.). Sin embargo, los trabajos sobre educación, instrucción, etc. han tenido cabida en revistas especializadas desde su fundación (ejemplo, Cognition e Instructiori). Si adoptamos los criterios que Gardner utiliza para identificar los rasgos clave de la ciencia cognitiva, podemos concluir que participa de todos ellos, con una sola excepción: representaciones (símbolos, reglas, imágenes), ordenadores, creencia en los estudios interdisciplinares, arraigo en los problemas filosóficos clásicos (experiencia, razón, conocimiento, intencionalidad, mente).

Con la vista puesta más acá de 1985 (año de publicación de la obra de Gardner) habría, hay, que decir que no hay excepción alguna, y que la coincidencia es plena ya que el autor de The mind's new Science sólo reclama para las ciencias cognitivas una característica más: su menor preocupación Ode-emphasis) sobre el afecto, el contexto, la cultura y la historia(24). Veinte años después, resultaría arriesgado sostener el juicio sobre tamaña falta de preocupación, aunque es cierto que hasta entrados los años noventa no se han planteado en profundidad los problemas y aspectos citados en algunas de esas disciplinas. En todo caso, la educación no puede pensarse al margen de cómo el hombre representa, vive, narra, la experiencia de afecto, la experiencia cultural, histórica y de interpenetración con el contexto(25).

(24) Gardner, op. cit., pp. 41-42.

(25) janer, G. (2002). Representación del mundo y conflicto moral. Revista de Educación $\left(n^{\circ}\right.$ extraordinario sobre Educación y Futuro), pp. 7-12; según Janer, «el hombre capaz de narrarse es el hombre capaz de actuar, de ajustarse a normas, de ser un sujeto moral» (p. 8); ¿y qué otra cosa es el hombre educando? 
Se pueden formular diversas razones para reivindicar el papel de la cultura en la formación de las representaciones mentales: los seres humanos no terminan en su propia piel y, gracias a la cultura, el significado de la acción humana se hace pública(26).

Más específicamente, la pedagogía cognitiva se ocupa y preocupa de diversos temas relacionados con el aprendizaje, el conocimiento, el razonamiento, la emoción, la memoria, el cerebro y los ordenadores, por un lado, y con los procesos de cambio, sobre todo de innovación, en las organizaciones (sistemas, ciudades) educativas, por el otro. En el punto presente nos ocuparemos de las cuestiones relacionadas con el primer bloque de cuestiones, dejando el resto para el siguiente, en el que también se atenderá a cómo debe pensarse la educación desde esta misma perspectiva cognitiva.

Uno de los tópicos básicos de la pedagogía cognitiva es el aprendizaje basado en problemas. Enraizado en la pedagogía del siglo XX, ha adquirido una mayor vigencia por el acrecido interés respecto de la formación en competencias ya que, sobre todo en la educación superior, la competencia de resolución de problemas es una de las más demandadas. El thesaurus del ERIC relaciona el descriptor «aprendizaje basado en problemas» de forma subordinada respecto de procesos cognitivos y lo define como «cualquier proceso educativo que comprometa a los estudiantes a investigar y resolver cooperativamente uno 0 más problemas, de duración indefinida de la vida real». Este descriptor se relaciona lateralmente con otros tales como: Case Method (Teaching Technique); Clinicai Experience; Cooperative Learning; Criticai Thinking-, Clinicai Experience-, Cooperative Learning-, Criticai Thinking-, Discovery Learning; Experiential Learning-, Learning Activities; Learning Strategies; Problem Solving; Problems. Dada la tradición de aplicación educativa en el campo de las Ciencias de la Salud, se incluye también en

(26) Vázquez, G. y Bárcena, F. (1999). Pedagogía cognitiva: la educación y el estudio de la mente en la sociedad de la información. Teoría de la Educación. Educación y Cultura en la Sociedad de la Información, (1), p. 10. 
este listado de términos conexos el de Medical Education, campo en el que, como es sabido, se ha desarrollado mucho el tópico de la competencia clínica.

Podemos identificar las raíces del método de aprendizaje basado en problemas en la obra de Dewey; por ejemplo, en Democracia y Educación, en la que enumera los pasos de una experiencia reflexiva en estos términos: a) perplejidad, confusión, duda debido al hecho de que uno se encuentra implicado en una situación incompleta cuyo carácter pleno no está todavía definido; b) una anticipación conjetural; c) un examen cuidadoso del problema; d) la elaboración consiguiente de la hipótesis tentativa más precisa y consistente; e) un plan de acción para la verificación de la hipótesis y la resolución de la dificultad(27). Como se ve, el primer paso requiere una formación para tolerar y manejárselas bien con la incompletitud de una situación. A partir de esta situación problemática se desarrolla un proceso de pensamiento científico que se puede entender análogo respecto del propio del «sentido común», tal como el mismo Dewey plantea en Hoiv We $\operatorname{Think}(1910)^{(28)}$.

La cuestión básica que interesa aquí es la de la relación entre el aprendizaje basado en problemas y el conocimiento previo que posee el estudiante. De acuerdo con el thesaurus de ERIC podemos entender el aprendizaje previo como «el aprendizaje formal 0 informal que tiene lugar antes de entrar en un programa específico; frecuentemente se evalúa para determinar el reconocimiento del conocimiento previamente alcanzado (el aprendizaje previo puede incluir el aprendizaje experimental)». Esta definición asegura la importancia de realizar la evaluación inicial en el momento de ingresar en un programa y nos confirma que, dentro de un enfoque de aprendizaje a lo largo y ancho de la vida, cada vez es más necesario evaluar

(27) Dewey, J. (1916). Democracy and education. N. York: Macmillan Co. Traducción española: Democracia y educación. Madrid: Morata, 1995. (Punto: la reflexión como experiencia).

(28) Dewey, J. (1910). How we Think. Lexington, Mass: D. C. Heath. Traducción española (1989): Cómo pensamos. Cognición y desarrollo humano. Barcelona: Paidós. 
y acreditar las competencias previamente adquiridas. Así mismo, de este modo se certifica el carácter sistémico de la educación.

Nos planteamos aquí si el aprendizaje basado en problemas asegura una buena conexión entre la identificación y resolución del problema y el conocimiento previo. Como se ha dicho antes, el campo en el que se ha investigado más es el de la formación médica, campo en el que no hay una evidencia todavía suficiente. Así, mientras en la revisión de Colliver (2000) se concluye diciendo que no hay evidencia convincente de que el Aprendizaje Basado en Problemas (.PBL) mejore la base de conocimiento y la ejecución clínica (al menos no tanto como se espera y como cabría esperar de los costes que genera el modelo(29), no faltan trabajos que confirman la hipótesis de que se producen resultados significativos cuando se produce la integración de nueva información con las estructuras de conocimiento preexistente activadas por la experiencia de aprendizaje basada en problemas(30). En cualquier caso, parece confirmarse que en el proceso de construcción social del conocimiento la instrucción orientada a los problemas no puede renunciar a contar con la base de conocimientos adquirida a través de procedimientos ordinarios (relación profesor-estudiante, consulta de fuentes básicas).

En el proceso de modificación cognitiva se encuentran dos fuentes de variación significativas: la formación y la evolución cronológica de carácter positivo 0 negativo (involución 0 deterioro). También, la competencia cognitiva es contingente respecto de la calidad de la relación entre la propia cognición (cognición racional) y la emoción. El dinamismo del proceso de llegar a ser experto reconoce cinco estadios diferenciados: principiante, principiante avanzado, perito, competente y experto. Los estudios actuales confirman en lo fundamental los ya clásicos de Dreyfus 29302930

(29) Colliver, J. (2000). Effectiveness of problem-based learning curricula. Research and theory. Academic Medicine, 75, pp. 259-266.

(30) capón, N., and Kuhn, D. (2004). What's so good about problem-based learning. Cognition and Instruction, 22 (1), pp. 61-79. 
y Dreyfus acerca de las diferencias entre los modos de razonar y de actuar los sujetos de los estadios más alejados(31) Según Hmelo-Silver y Pfeffer (2004), las representaciones de los novicios se focalizan en la información perceptivamente disponible, en componentes estáticos del sistema, mientras que las de los expertos se orientan hacia los componentes estructurales y funcionales y hacia el nivel de comportamiento del sistema(32) En algunos estudios recientes en el ámbito de los profesionales de la salud se concluye que la ejecución del experto es una combinación de conocimiento base, destrezas de razonamiento y un acúmulo de experiencias con pacientes que es cualitativamente diferente de los competentes y, más aún, de los principiantes(33)

En términos generales, se acepta que el experto comprende los problemas en términos situacionales e interactivos con el contexto, de manera más abierta, y es más eficaz en la identificación y resolución de problemas caracterizados por su complejidad e incertidumbre. En el caso de los profesionales de la educación (profesores, orientadores, directivos, formadores, etc.) se considera que su comportamiento interactúa fuertemente con sus creencias o teorías implícitas acerca de la educación, de los alumnos, de los profesores y trabajadores, etc., sobre todo en situaciones pre-profesionales y en el principio de su experiencia práctica, pero también a lo largo de la vida de los profesionales con abundante experiencia. Estas creencias y teorías no siempre son explícitas, pero actúan como verdaderos antecedentes del comportamiento de los estudiantes a través de la conducta del profesional, de sus expectativas y de las creencias y expectativas generadas en el sujeto al que se está formando. Este enfoque resulta útil para analizar y corregir 313233313233

(31) Dreyfus, H. L. and Dreyfus, S. E. (1986). Mind over machine. N. York: Free Press.

(32) Hmelo-Silver, C. E. and Pfeffer, M. G. (2004). Comparing expert and novice understanding of a complex system from the perspective of structures, behaviors, and functions. Cognitive Science 28, pp. 127-138.

(33) Crespo, K., Torres, J. E., and Recio, M. E. (2004). Reasoning process characteristics in the diagnostic skills of beginner, competent, and expert dentist s. Journal of Dental Education, 68(12), pp. 1235-1244. 
los errores de los profesionales y para poder explicar por qué fallan en la práctica las teorías explícitas conocidas por ellos; igualmente es valioso en relación con el conocimiento de los estilos docentes, directivos, etc. de los profesionales.

Las «teorías» (generalizaciones del conocimiento) de los profesionales son más o menos explícitas según la cantidad de su experiencia. Ordinariamente se acepta que las teorías de quienes están más cerca del dominio y de experticia, pese a estar más consolidadas, son menos explícitas que las de los novicios y principiantes avanzados. En el proceso formativo de éstos resulta fructífera la relación con los más expertos, de tal modo que se puede sostener que la calidad del aprendizaje de los noveles se incrementa si se produce un diálogo adecuado (acerca de las destrezas prácticas y, sobre todo, de la forma de razonar) entre unos y otros (Akre y Lugvidsen, 1997, para el caso de los médicos expertos y en formación(34)) Este hallazgo debería confirmarse en las situaciones del practicurn de los universitarios y profesionales en la transición hacia la vida activa. La creación de los sistemas basados en conocimiento (dentro de la Inteligencia Artificial) se ha generado precisamente dialogando con expertos con importantes competencias cognitivas (por ej.: en el diagnóstico médico, en el reconocimiento de patrones en el ajedrez, directores de orquestas sinfónicas, etc.) y observando cómo aplican sus propios procesos de razonamiento en la ejecución de la tarea.

La competencia cognitiva de los expertos se caracteriza, además, por otras dos características: el aprendizaje y la cognición en contextos naturales y su mayor dominio en la comprensión de la complejidad. Los sujetos aprenden a dominar los problemas propios de una situación en contextos «naturales» ordinarios, en situaciones familiares, aunque a veces lleguen a adquirir una gran complejidad. La dificultad de comunicarse un experto

(34) Akre, V, and Ludvigsen, S. R. (1997). How to learn medical practice? A qualitative study of physicians' perception of their own learning process. Tidsskrift for den Norske Laegeforening, 117 (19), 2757-2761. Este estudio muestra que, cuando los profesionales promocionan en su posición en la jerarquía dentro de los hospitales, mejoran su competencia respecto de la descripción de sus propios procesos de aprendizaje. 
y un principiante se produce en términos de la contraposición entre los planes de acción orientados a situaciones típicas y las construcciones y reconstrucciones de las acciones no típicas y más fuertemente dependientes de los contextos. En el terreno de la educación, se han contrapuesto los paradigmas cognitivista y del aprendizaje situado caracterizando los planes del aprendizaje cognitivo como más dependientes de los prerrequisitos y de la intencionalidad, mientras que los del aprendizaje situado operan de una forma más próxima a la reconstrucción racional de la acción, contingente con las variaciones situacionales y con la distribución del conocimiento y poniendo menor énfasis en la intención y mayor en la comunicación sobre la acción(35)

La ciencia muestra actualmente mucho interés en el estudio de la relación entre cognición y desarrollo, sobre todo en dos ámbitos, en el de la evolución de la cognición, y en el de la relación entre cognición y envejecimiento. Ambos se basan en la distinción entre sistemas reactivos y sistemas cognitivos; pese a la eficiencia de aquéllos, es preciso reconocer sus límites para funciones y tareas tales como pensar y planificar acciones. Importa estudiar aquí cómo se establecen los modelos internos acerca de la acción y cómo ciertos organismos inteligentes no sólo reaccionan a las perturbaciones del entorno sino que también inician 0 emprenden las acciones, se forman representaciones internas acerca de cómo es el mundo exterior, anticipan la representación de cómo quedaría modificado ese mundo a partir de una determinada acción sobre el mismo y actúan consecuentemente (Jeannerod, 1997)(36) Este proceso refleja de forma bastante aproximada cómo se produce la acción humana sobre el entorno (por ejemplo, en una acción de carácter pedagógico). Precisamente son los sistemas cognitivos aquéllos que

(35) streibel, M. J. (1993). Diseño instructivo y aprendizaje situado: jes posible un maridaje? En McClintock, R. O., Streibel, M. J. y Vázquez, G. (1993). Comunicación, tecnología y diseños de instrucción: la construcción del conocimiento escolar y el uso de los ordenadores (pp. 86 y siguientes). Madrid: MEC-CIDE. Las reflexiones sobre la epistemología del aprendizaje situado y su aplicación al diseño instructivo parten de los conocidos trabajos de Suchman y de Brown, Collins y Duguid sobre los planes y las acciones situadas.

(36) jeannerod, M. (1997). The cognitive neuroscience of action. London: Blackwell. 
son capaces de planificar de forma preventiva, y no simplemente reactiva, los que actúan a partir de representaciones y modelos internos acerca de las propiedades del mundo, representaciones «libres de contexto» que actúan de modo dinámico generando productos (conocimientos y nuevas representaciones) de carácter simbólico(37).

La pedagogía debe interesarse más por el problema de la relación entre envejecimiento y cognición. Si consideramos la educación desde la perspectiva de la educación a lo largo de toda la vida, y teniendo en cuenta la prolongación en la expectativa de vida y el desarrollo de la pedagogía de la vida adulta, resulta necesario asegurarse de que los estudiantes universitarios estén más familiarizados con la cognición en la adultez y la ancianidad(38). Las ciencias cognitivas, y sobre todo la neurobiología y la psicología cognitivas, muestran un interés progresivo por el efecto del envejecimiento sobre la cognición (sobre el número y conectividad celular y neuronal) y acerca de los distintos efectos que el deterioro mental produce sobre diversos estilos cognitivos. En este punto, se admite que tal deterioro es más acusado en individuos y procesos de inteligencia fluida (ejemplo: procesos de razonamiento) y menor en sujetos de estilos y procesos cristalizados (ejemplo: procesos de acumulación de información). Un problema específico de investigación es el de la interacción entre los procesos de maduración y envejecimiento de los educadores, según su propio estilo cognitivo, y los estilos cognitivos (diversos dentro de una clase) de los estudiantes.

Otro campo al que una pedagogía cognitiva debe prestar mayor atención es el de la emoción. Se puede afirmar que, durante la mayor parte del siglo $\mathrm{XX}$, tanto la psicología como la pedagogía parecen «haberse olvidado» de la emoción y de su papel en los procesos de razonamiento. En la actualidad,

(37) Cruse, H. (2003).The evolution of cognition, a hypothesis. Cognitive Science, 27 (1), pp. $135-155$.

(38) La OCDE ha desarrollado su Programa sobre Leaming Sciences and Brain Research en tres escenarios: los aprendizajes tempranos, los aprendizajes juveniles y la vejez, respectivamente en N. York (junio de 2000), Granada, España, (febrero de 2001) y Tokio (abril de 2001). 
la discusión científica se está abriendo a «la (otra) lógica de la emoción», tanto como resultado de la investigación neuroanatómica y fisiológica cuanto en relación con la construcción del conocimiento (se ha dicho «las emociones son actos sociales», aunque cabe distinguir entre un momento y una experiencia subjetivos de la emoción, el sentimiento, y su proyección social exterior). Este mayor interés se ha proyectado también sobre la relación emoción, memoria y aprendizaje(39), así como con la comprensión de la propia expresión emocional y de la de los demás. Esta línea de trabajo adquiere un interés acrecentado en la acción pedagógica en situaciones de análisis y acción sobre situaciones de conflicto (en la comunidad, en las organizaciones, en las familias, en el aula, etc.). Aunque el exceso de emoción puede oscurecer la razón lógica, una cierta competencia emocional es, como ha señalado Morin, indispensable para poner en práctica comportamientos racionales(40). Del mismo modo, se está revalorizando la educación de la intuición, uno de los principios pedagógicos clásicos que desgraciadamente han caído en la inobservancia; en palabras de Hoghart, éste es un reto para la educación de nuestro tiempo(41).

Los estudios sobre el cerebro visual han permitido profundizar en la comprensión de la obra de arte y de los fundamentos neurológicos de las leyes que regulan la creatividad y la apreciación artísticas. Zeki (2004) ha analizado los procesos creativos del Dante (La Divina Comedia), Miguel Ángel (en la escultura y la poesía), Vermeer (.Muchacha con el pendiente perla) y Wagner (Tristán e Isolda') respecto del amor como ideal y argumenta que los procesos de creación artística responden a una ley universal de la actividad cerebral, a saber, la de crear ideales como producto de los procesos

(39) Damasio, A.R. (1994). Descartes' error: Emotion, reason and the human brain (chapter 7: Emotions and feelings, pp. 127-164). New York: Avon Books.

(40) Morin, E. (2001). Los siete saberes necesarios para la educación del futuro. Barcelona: Paidós, p. 27.

(41) Hoghart, R. M. (2003). Educar la intuición: Un reto para el siglo XXI. Barcelona: Els Opuscles del CREI, n 13 . 
abstractivos del cerebro(42) En todas estas obras está presente la lógica de lo inconcluso, de la ambigüedad, de la aproximación al ideal, de la obra de arte no resuelta (artista, intérprete y espectador quedan ab/sortos y ab/ sueltos respecto de la propia obra artística)(43) Estas características generan productos inacabados e infinitos: el propio autor no es conocido (tal como expresó Marcel Proust respecto de Vermeer, y que también habríamos de decir del mismo Proust, un artiste à jamais inconnu); la consideración de Zeki acerca de que el gran arte, la obra maestra, es aquélla que se corresponde con múltiples y diferentes conceptos en el mayor número posible de cerebros resulta muy fecunda sobre una teoría de conceptos en el arte, de una teoría del conocimiento distribuido y la pedagogía de la creatividad. Entre esos cerebros se encuentran tanto el del pintor, músico, poeta 0 escultor (como creadores de la obra de arte), cuanto el del espectador (como recreador de la misma). La característica de lo creativo, según Heidegger, hace que, por ejemplo, un diálogo de Platón sea inagotable, no solamente para la posterioridad con su concepciones sujetas al vaivén de los tiempos, sino en y por sí mismo, por su propia esencia(44).

Finalmente, una teoría de la educación de orientación cognitiva se plantea el problema de la mente, de la relación mente-cuerpo y el más básico de la relación mente-mente(45). La teoría computacional de la mente considera que la mente es un ordenador digital, esto es, un dispositivo de estados discretos que almacena representaciones simbólicas manejadas mediante

(42) Zeki, S. (2004). Formación del concepto neural del arte: Dante, Miguel Ángel y Wagner. En F. Mora (Coord.), Op. cit. (pp. 392-425).

(43) L relación entre el arte y el conocimiento se ha estudiado en: Bruner, J. S. (1969) On knowing. Essays for tbe left hand. N.York: Atheneum (cap. «Art as a mode of knowing»).

(44) Heidegger, M. (1972). ¿Qué significa pensar? Buenos Aires: Nova, p. 27.

(45). Aunque está muy extendida la formulación del problema en estos términos contrapuestos, hay críticos a cualquier forma de dualismo. Así, por ejemplo, Searle, J. R. (2001). Mente, lenguaje y sociedad. Madrid: Alianza. Afirma el autor que no le parece que ni el dualismo, sea el de la sustancia 0 el de la cualidad, ni el materialismo en cualquiera de sus formas, tenga ninguna oportunidad de acertar, y que el hecho de que sigamos planteando e intentando resolver estas cuestiones en el anticuado y obsoleto vocabulario de «mental» y «físico», de «mente» y «cuerpo», debería ser una advertencia de que estamos cometiendo algún error conceptual fundamental en el modo en que formulamos las preguntas y las respuestas (p. 52). 
reglas sintácticas y que los procesos mentales son secuencias causales guiadas por las propiedades sintácticas de los símbolos, no por las semánticas(46). Esta teoría, formulada inicialmente por Putnam, en 1975, y mantenida por otros autores (entre ellos por Fodor y Pylyshyn), ha recibido, pese a su uso extendido, críticas desde distintas perspectivas: la de los sistemas dinámicos adaptativos, la de la dificultad de reducir pensamiento y comportamiento humanos a reglas explícitas programables en un ordenador y, finalmente, la relativa a que las representaciones existentes en los ordenadores no son sino las que se derivan de las intenciones y representaciones de sus usuarios (de esta forma, puede decirse que los sistemas cognitivos mantienen su relación con su entorno cultural). Una de las aplicaciones actuales de los sistemas de procesamiento de la información es la de las redes neuronales, sistemas que intentan emular, imitando el procesamiento distribuido, las capacidades de percepción y reconocimiento del cerebro humano(47).

La cuestión de fondo, formulada en palabras de Jackendoff, es qué hace a nuestra experiencia consciente ser como es(48) La propuesta de este autor reconoce que nuestra contribución interna al mundo es tan rica, compleja y vital como la contribución de la «realidad externa» y que el conocimiento y los valores humanos están enraizados en la herencia biológica (en la biológicocultural, cabría precisar). Esta forma de concebir la conciencia, relacionada con otros rasgos esenciales de los fenómenos mentales (intencionalidad, subjetividad y «causación» mental) se aleja de las teorías de la mente de corte materialista a las que Searle ha llamado teorías inverosímiles y que acogen ideas sobre la IA, en su sentido más fuerte, y que niegan la introspección y que niegan la posibilidad de la conciencia de sí mismo como mí mismo(49)

(46) Horst, S. (2002). Teoría computacional de la mente. En R. A. Wilson y F. C. Keil (Eds.), Enciclopedia MIT de las ciencias cognitivas (pp. 1264-1266). Madrid: Síntesis.

(47) COTEC (1998). Redes neuronales. Madrid: editor (Documentos COTEC sobre oportunidades tecnológicas).

(48) jackendoff, J. (1998). La consciencia y la mente computacional. Madrid: Visor, p. 11.

(49) searle, J. R. (1996). ¿Qué marcha mal en la fillosofía de la mente? En J. T. Searle, El redescubrimiento de la mente (pp. 15-40). Barcelona: Crítica. 
En cualquier caso, existe todavía hoy un amplio acuerdo en la vigencia de la paradoja computacional que Gardner formulara en 1985, lo que explica su uso extendido:

La paradoja descansa en el hecho de que (...) sólo a través de una escrupulosa adherencia al pensamiento computacional pueden descubrir los científicos los modos en los que los humanos difieren actualmente del ordenador digital serial, del ordenador de Neumann, modelo que ha dominado el pensamiento de los científicos cognitivos de la primera generación(50).

La ciencia cognitiva ha crecido gracias a los estudios sobre las analogías, paradojas, paralogías y otros juegos de lenguaje. Uno de esos juegos (la paradoja computacional) ha pertnitido que incluso quienes creen que la inteligencia natural y los sistemas humanos inteligentes no se pueden «encerrar» en los registros de la inteligencia artificial hayan aprendido sobre estos sistemas gracias a las aportaciones de la tecnología digital. Pero, también, y en el sentido contrario, de la misma forma que nos preguntamos cuánto saber anida en el conocimiento y cuánto conocimiento en la información (archivada y recuperable en forma digital), deberíamos cuestionarnos cuánto potencial de razonamiento, pensamiento y simbolismo perdemos al suprimir la analogía (tan fecundo en la filosofía y en la literatura, y también como metáfora científica) como forma de acceso a un conocimiento posiblemente verdadero.

\section{La Teoría de la Educación ante las necesidades y las deman- das actuales de los sistemas educativos}

Observando las indicaciones de Gardner acerca de las características de las ciencias y disciplinas cognitivas y la propuesta de Bunge sobre la filosofía 
de la tecnología(51), podemos aceptar que la pedagogía es una tecnología cognitiva. ¿Cuál es, pues, el papel de la pedagogía, y de su núcleo teóricotecnológico-cognitivo, ante las exigencias de la sociedad y ante la actual sociedad que hemos calificado como Sociedad de la Información?

Antes de contestar a la primera parte de la pregunta resulta conveniente hacernos cargo de la cuestión, planteada por Castells, acerca del concepto mismo de «Sociedad de la Información». Según este autor, la sociedad actual se caracteriza por tres rasgos: su carácter informacional, su dimensión global y su característica estructura en red(52) En $i_{\text {os }}$ últimos años los estudiosos del tema, como el propio autor, han desplazado su centro de interés, desde la información a la peculiaridad de la estructura reticular. Resulta, por lo tanto, pertinente plantearnos cuáles son las características propias de la red y del vivir 0 trabajar en red (network, networking, ...). Esas características nos remiten a la existencia y uso de vínculos internos y externos, antecedentes y derivados de procesos de comunicación, interacción y coordinación, entre personas, equipos humanos y organizaciones para mejorar su actuación efectiva(53)

Esta propuesta acerca de la convivencia y competencia en red es compatible con las teorías y creencias acerca de la convergencia entre competencia y competitividad y sobre el conocimiento compartido, cooperativo y distribuido. Sin embargo, esta forma de entender las relaciones de pertenencia social plantea el grave problema de las relaciones de inclusión y exclusión social en la Sociedad de la Información. En mundos tales como el de las empresas, en el del sistema de ciencia y tecnología, en el propio mundo académico, «quien no está en la red, no existe». Esta forma de concebir y valorar las ${ }^{515253515253}$

(51) Bunge, M. (1985). Treatíse on Basic Pbilosopby, vol. 7, Parí II: Life Science, Social Science and Technology. Dordrecht-Boston: Kluwer Academic Publishers. En esta obra se concluye que la psicología y la pedagogía son sendas tecnologías psicosociales, concebidas como cuerpos de conocimiento aplicado a la identificación y resolución de problemas de esa naturaleza.

(52) Castells, M. (2001). Materiales para una teoría preliminar sobre la sociedad de redes. Revista de Educación (n ${ }^{0}$ extraordinario sobre Globalización y Educación), pp. 45-46.

(53) OECD (2003). Networks of innovations: Towards new modelsfor managing schools and Systems. Paris: editor, p. 34. 
cosas plantea algunos problemas dentro de estos ámbitos, pero resulta mucho más grave en el espacio de la participación social y cívica dentro de la sociedad. Una primera tarea de la pedagogía cognitiva es la de hacerse cargo de la falta de homogeneidad social en el uso de la información y de sus herramientas de acceso y transmisión y de asignación de significado.

$\mathrm{Si}$, como se ha dicho al principio de este trabajo, cada sociedad y cada tiempo genera nuevos deberes y nuevos pactos sobre la educación, resulta necesario considerar que una de las primeras obligaciones intelectuales, y por ende éticas, de la pedagogía es la de hacerse cargo del potencial excluyente que se esconde debajo de las expresiones «brecha digital», bien se refiera a sujetos, a grupos y comunidades o a generaciones. Concebida la cultura como una medida homogénea que facilita las relaciones de pertenencia y de atribución de significados, pocos riesgos más graves en la actualidad que los derivados de una tecnología (la de la información) que, lejos de actuar como vínculo de cohesión social, expulsa a individuos y grupos fuera del tejido social ${ }^{(54)}$.

El problema de la brecha digital nos plantea dos problemas, el de la separación por razón de uso o de propiedad de la tecnología, y el de la naturaleza de la información albergada en esta sociedad. Sobre lo primero, el problema de la tecnología se puede reconocer como un problema de origen: «la tecnología se crea en respuesta a las presiones del mercado», lejos de las exigencias y necesidades genuinas de la educación; de aquí que sea necesario «poner la tecnología al servicio del desarrollo humano" tal como viene requiriendo el PNUD ${ }^{(55)}$. Pero, viniendo más de cerca al terreno pedagógico, es preciso si esta brecha digital es la más grave ruptura que

(54) Las Nuevas Tecnologías de la Información tienen un gran potencial de inclusión social. Cfr.: Prats, E. (2005). Redefinición de lo educativo en el cibercontexto: a propósito de las TIC como herramienta de inclusión. Teoría de la Educación. Educación y Cultura en la Sociedad de la Información, 6 (1) ( $\mathrm{N}^{\circ}$ monográfico sobre «Las TIC como herramienta de participación e inclusión social para jóvenes en situación de riesgo»).

(55) PNUD (2001). Informe sobre Desarrollo Humano 2001. poner el adelanto tecnológico al servicio del desarrollo humano. Madrid: Mundi-Prensa Libros. Recuperado de la World Wide Web el 20 de junio de 2005. http://hdr.undp.org/reports/global/2001/en/). 
nos podemos encontrar en la educación. Siguiendo la lógica del desarrollo tecnológico y de «la imposición tecnológica», tiende a considerarse que la solución a los problemas del analfabetismo tecnológico y digital se encuentra en instalar más ordenadores e incrementar la malla de la red. Sin embargo, aunque se llevaran a cabo las previsiones de Kaku acerca del desarrollo tecnológico en las aulas y en los hogares (una radio, un periódico digital, un ordenador en cada pared, cableando o dotando de red inalámbrica todo el espacio,...)(56) ? no llegaríamos a superar la división digital pues, como ha señalado Haddad, «la más grave división reside en la extensión y calidad del conocimiento y el aprendizaje-, no es digital, es educacional»(57).

La verdadera y acaso más oculta forma de exclusión educativa es la de las diferencias en la calidad de la información a la que se tiene acceso. Éste es un argumento que no se puede olvidar en el contexto de la evaluación de los aprendizajes y de los sistemas educativos. Programas, por otra parte relevantes, como el PISA o el TIMMS, orientados a evaluar los resultados de aprendizaje en la matemática, la ciencia y la tecnología (incluso en la lengua, como en el primer caso) suponen el grave riesgo de olvidar que la calidad de la información depende en buena medida de la calidad (importancia, significación cultural, veracidad, pertinencia, etc.) de su contenido. Y que las facilidades en el acceso a la información no resuelven por sí solas la participación en el conocimiento y el logro de un saber personal puesto al servicio del desarrollo personal y de la comunidad. Una pedagogía social de orientación cognitiva debe empeñarse en el logro del restablecimiento del diálogo, dentro y entre las comunidades, entre quienes conservan vivo el pensamiento, el conocimiento y el lenguaje (en su dimensión narrativa y mnésica) y quienes están digitalmente alfabetizados 58

(56) Kaku, M. (1998). Visiones. Cómo la ciencia revolucionará la materia, la vida y la mente en el siglo XXI. Madrid: Debate.

(57) OECD (2000). Leaming to bridge the digital divide, (cfr. el cap. 4, de Haddad, titulado: Emerging trends and issues: The nature of the digital divides in leaming, p. 52.). Paris: editor.

(58) Vázquez, G. (2003). Sociedad-red, ciudadanía cognitiva y educación. Revista de Educación (n ${ }^{0}$ extraordinario sobre Ciudadanía y Educación), 25- 
Esta tensión tiene una vigencia especial en el diálogo intergeneracional dentro de una misma familia 0 comunidad y en situaciones de migración.

En el proceso continuo de repensar el papel actual de la escuela es necesario considerar que la educación es un proceso longitudinal y transversal que se da «a lo largo y a lo ancho de la vida». Aunque los organismos internacionales (UNESCO, OCDE, Banco Mundial, etc.) exigen un compromiso total con una educación de calidad para todos, todavía estamos lejos de articular una idea acerca del sistema educativo global que comprometa e integre todos los esfuerzos, recursos y capacidades de todas las agencias directa 0 indirectamente educativas (familia, escuela, ciudad, organizaciones productivas, medios de comunicación, medios de creación y difusión cultural, administraciones y sociedad civil) (59). g simplemente una cuestión de supervivencia anclar la calidad de la educación en proyectos de calidad de vida para todos, tarea, nunca acabada, en la que una pedagogía tecnológica (cognitiva, del pensamiento) tiene mucho que hacer y no poco que pensar(60). Sólo se puede aspirar a lograr sujetos competentes dentro de comunidades educativas que actúen sinérgicamente y con vistas a una acción formativa a medio y largo plazo.

En la actualidad, conocemos muchos esfuerzos en pro de pensar y de construir una educación para la ciudadanía dentro de un proceso de construcción de la ciudad como espacio, no sólo transitable, sino, en última instancia, «vivible», flexible e interpretable(61). La consideración de la educación desde la perspectiva de los derechos humanos lleva a valorar el derecho a la participación en la ciudad tecnológica como uno de los

(59) $\mathrm{L}_{\mathrm{a}}$ familia tiene un gran potencial educativo en relación con la complejidad propia de la sociedad multicultural de nuestro tiempo aprovechando su propia configuración como vía para comprender otras realidades sociales únicas y. complejas; cfr.: Vázquez, G. (2004). Desenvolvemento cognitivo e formación da competencia persoal dentro da familia. Revista Galega do Ensino (44), 44.

(60) Vázquez (2002). El sistema educativo ante la educación de calidad para todos a lo largo y ancho de la vida. Revista de Educación ( $\mathrm{n}^{\circ}$ extraordinario sobre Educación y Futuro), pp. 39-57.

(61) Cfr.: Revista de Educación (n extraordinario sobre Ciudadanía y Educación). 
derechos de tercera generación ${ }^{(62)}$. La ciudadanía actual ha de considerarse hoy como ciudadanía cognitiva, esto es, como derecho de pleno derecho a participar efectivamente en la sociedad de la información. La «construcción» de «la ciudad del conocimiento» no debe entenderse sólo como construcción física de una ciudad cableada, con brechas y zanjas abiertas por doquier, que, como las autopistas o las vías rápidas, separan a unos de otros, y que son objeto de estudio y trabajo de arquitectos, geógrafos y urbanistas, sino también de una forma, cognitiva, de ver los problemas de aprendizaje y comunicación que se generan por esta vía. Es, también, una cuestión formalmente pedagógica $(63)$.

La construcción de la educación, como un tejido, a lo ancho de la vida y su situación dentro una sociedad en red, globalizada y multicultural obliga a que la pedagogía tenga que adoptar una perspectiva necesariamente compleja. El paradigma de la complejidad, nacido en el ámbito de las ciencias experimentales y que posteriormente se aplicó a las ciencias sociales, se ha adoptado por la teoría de la educación. La complejidad es un fenómeno y un paradigma que interesa a la Pedagogía desde varias perspectivas: la del análisis, comprensión y decisión sobre las situaciones educativas; la antropológica (el cerebro humano como expresión de la máxima complejidad ${ }^{(64)}$ ); la del análisis y prospectiva de los sistemas educativos y la de carácter epistemológico en relación con el carácter científico de la pedagogía. El enfoque de la complejidad es necesario para estudiar cualquier tipo de problema o situación educativa y, de forma más acusada, en campos como los de la educación «ambiental», multicultural, la formación de profesores y directivos, etc. ${ }^{(65)}$; por otra parte, este enfoque

(62) Touriñán, J. M. (1999). Globalización, desarrollo y política regional. En P. Ortega y R. Mínguez (Coords.), Educación, Cooperación y Desarrollo. Murcia: Cajamurcia, pp. 35-67.

(63) Puede verse un ejemplo de la preocupación de los tecnólogos por este problema en: COTEC (2004). La ciudad del conocimiento. La respuesta de la tecnología a los retos urbanos. Madrid: editor. Recuperado, el 25 de junio de 2005, de la World Wide Web: http://www.cotec.es.

(64) Asensio, J. M. (1997). Biología y educación (capts. 1 y 2). Barcelona: Ariel.

(65) Asensio, J. M. (2000). La formación del docente en y para la complejidad. Teoría de la Educación, 12, pp. 29-43. 
se aplica dentro de los campos de la gestión de organizaciones educativas, la pedagogía social y del trabajo, etc.

El pensamiento pedagógico es deudor del razonamiento analítico y del método hipotético-deductivo. Pero hay muchos problemas, y campos de problemas, que se resisten a su comprensión, explicación y previsión mediante una lógica científica de carácter convencional. La naturaleza de los problemas, su relación con el contexto, su historia deben aconsejar utilizar unas vías u otras de tratamiento. Como se señalado Colom, la comprensión del mundo desde el análisis y desde la complejidad nos aporta dos narrativas diversas, ambas igualmente correctas; al orden que impone el análisis podemos oponerle «el orden caótico» que se adivina en la complejidad; ambas posiciones son, sin más, igualmente correctas(66).

Una de las aportaciones más enjundiosas del enfoque de la complejidad aplicado al estudio de los problemas y de las acciones educativas es la de considerar que los sistemas abiertos, complejos (en nuestro caso los sistemas educativos, las organizaciones formativas, los centros educativos, las familias, el propio hombre como educando, el cerebro humano) constituyen sendos ejemplos de estructuras disipativas, esto es, de estructuras que tienen capacidad de autoorganizarse y que, para ello, consumen una gran cantidad de información(67). Esta idea acerca de la educación confirma la necesidad de comprenderla dentro de procesos que duran y se extienden a lo largo y ancho de la vida.

Una particular aportación de la educación al Sistema de Ciencia y Tecnología (STC) y, sobre todo, a los procesos de Investigación + Desarrollo + Innovación (I+D+i) es de las formas ordinarias de conocer, enseñar y

(66) colom, A. J. (2002). La (de) construcción del conocimiento pedagógico. Nuevas perspectivas en teoría de la educación (p. 147). Barcelona: Paidós.

(67) g t campo es muy considerable la aportación de los estudios de Prigogine. Véanse: Prigogine, 1 . (1997). El fin de las certidumbres. Madrid: Taurus; Prigogine, I. (1999). Las leyes del caos. Barcelona: Crítica; Nicolis, G. y Prigogine, I. (1994). La estructura de lo complejo. Madrid: Alianza (los puntos 2.1 y 2.2 de esta obra tratan, respectivamente, de los sistemas conservativos y sistemas disipativos). 
aprender la información científica ${ }^{(68)}$. Éste es el campo de la pedagogía de la ciencia, uno de las líneas de trabajo de la pedagogía cognitiva. La preocupación por la vinculación entre desarrollo científico y desarrollo educativo, y la dependencia de aquél respecto de éste, ocupa la mayor parte del medio siglo de existencia de la ciencia cognitiva. Ya en 1959 Kuhn se ocupaba del tema, que habría de recogerse después en los conocidos Segundos Pensamientos, de la tensión esencial entre tradición e innovación en la investigación científica y de la contribución de la metodología de enseñanza y del contenido de los libros de texto al cambio científico ${ }^{(69)}$.

Un cuarto de siglo más tarde, el informe A Nation at Risk, cuando los Estados Unidos se encontraban todavía bajo los efectos del «choque (shock) del Sputnik, recogía en el punto cuarto de su segunda recomendación una relativa a que alos libros de texto y otros instrumentos de aprendizaje y enseñanza deben ser mejorados y puestos al día para asegurar un contenido más riguroso (70). Unos pocos años después, se recogía en España estas preocupaciones en sendos estudios de Fundaciones culturales

(68) La Escuela en todos sus niveles, incluidos los de la educación obligatoria, puede considerarse parte de los soportes a la innovación, al lado de los centros tecnológicos, los parques tecnológicos y científicos y los museos de la ciencia. Así se va reconociendo, aunque todavía de forma tímida, en los informes sobre los sistemas de información. Cfr.: Informe Soto (2003). Aprovechar la oportunidad de la Sociedad de la Información en España. Recomendaciones de la Comisión Especial de Estudio para el Desarrollo de la Sociedad de la Información [Informe Soto]. Madrid: editor (recuperado de la World Wide Web: http://cdsi. red.es/documentos/informe_final_cdsi.pdf). COTEC (2004). El sistema español de innovación. Situación en 2004. Madrid: editor.

(69) Kuhn, T. S. (1959). The Essential Tension: Tradition and Innovation in Scientific Research. En C. W. Taylor (Ed.), The Third (1959) University of Utab Research Conference on the Identification of Scientific Talent (pp. 162-174). Utah: Univ. Utah Press. Afirma Kuhn en este trabajo que suna de las características de las revoluciones científicas es que requieren que se escriban de nuevo los textos escolares (sobre todo de la educación secundaria) de las materias científicas. La lectura de estos pasajes nos trae a la memoria a los pedagogos la consideración de Ortega y Gasset acerca del anacronismo constitucional, del pensamiento pedagógico; en ambos casos se está reclamando una actualización del conocimiento disciplinar, bien de sus contenidos, bien de sus fundamentos.

(70) National Commission on Excellence in Education (1983). A Nation at Risk: The Imperative for Educational Reform. A Report to the Nation and the Secretary of Education United States Department of Education by The-- (Recommendation B: Standards and Expectations). 
y tecnológicas(71). Desde la perspectiva propia de la ciencia cognitiva interesa cómo se aprende y enseña la ciencia y, más concretamente, el estudio de los procesos de aprendizaje de los conceptos científicos (las representaciones mentales que favorecen u obstaculizan la adquisición del conocimiento) y las competencias cognitivas implicadas en el razonamiento científico. La suerte de estos procesos está condicionada en buena medida por los esquemas mentales aprendidos por los alumnos en la vida ordinaria (y que, con frecuencia, incluyen errores y concepciones ingenuas)(72) Las teorías sobre la matemática y la física ingenuas intentan dar cuenta de las posibilidades positivas y negativas de la intuición y de las creencias populares respecto de los conceptos científicos y de los procesos tecnológicos y de cómo se deben diagnosticar y controlar estos fenómenos en el campo de la enseñanza de las ciencias(73).

Por estas vías, la pedagogía de la ciencia está realizando contribuciones a la ciencia de la ciencia en paralelo a otras disciplinas (como la filosofía, la psicología, la sociología y la historia). Evidentemente, el rótulo «pedagogía de la ciencia» se aplica en un sentido ordinario, restrictivo, a los campos de las ciencias experimentales, de la matemática y de la tecnología, pero un sentido análogo más general habría de atribuirse igualmente a otros ámbitos conexos tales como la literatura, la música o la filosofía, sobre cuyos procesos mentales y de aprendizaje, y las valoraciones sociales, se ha desarrollado todavía poca investigación rigurosa.

(71) cfr:: García Carrasco, J. López, R. y Vacas, J. M. (1987). El uso de la informática en el contexto de la Educación Tecnológica. En G. Vázquez (Ed.), Educar para el siglo XXL Criterios de evaluación para el uso de la informática educativa (cap. V). Madrid. FUNDESCO; Fundación Santillana (1989). La Educación Postsecundaria ante la Sociedad del Conocimiento y de las Comunicaciones. Madrid: editor.

(72) García Milà, M. y Martínez, M. (1991). Ciencia cognitiva, habilidades del pensar y pedagogía de la ciencia. Revista Española de Pedagogía, 49 (188), pp. 147-162.

(73) cfr.: Proffitt, D. (2002). Física ingenua, pp. 527-528; y Gelman, R. (2002). Matemática ingenua en R. A. Wilson y F. C. Keil, (Eds.), Enciclopedia MIT de las ciencias cognitivas (pp. 780-782). 2 vols. Madrid: Síntesis. 


\section{Una conclusión, necesariamente abierta e insegura}

El desarrollo de las disciplinas cognitivas desde mediados del siglo XX ha permitido que la pedagogía, y dentro de ella su núcleo teórico-cognitivo, participe de la preocupación de la ciencia y la tecnología contemporáneas sobre el conocimiento. Años atrás se ha podido hablar en Europa de una pedagogía sistémica y cibernética, antecedentes en un cierto modo de la pedagogía cognitiva(74). En la última generación científica, desde hace unos quince años, lo cognitivo está tomando cuerpo dentro del conocimiento pedagógico, bien como contenido, bien como enfoque para considerar la educación en relación con otros campos y procesos de construcción de conocimiento, singularmente con la filosofía, la biología, la lingüística, la psicología y la tecnología(75).

Desde luego, la apertura de nuestra reflexión teórica a otros campos nos hace trabajar con préstamos tomados de otros campos científicamente más seguros, lo que genera un factor de riesgo añadido a la hora en la que los pedagogos intentan apoyar sus prácticas educativas en supuestos teóricos que no son genuinamente propios. En el paso de una pedagogía teórica a una teoría pragmática se presentan numerosos e importantes riesgos propios del quehacer que se deriva «de la debilidad teórica de la educación», cuyo discurso se muestra abierto a tantos relatos, muchos de ellos todavía fragmentarios(76).

Tamaña debilidad 0 , al menos, la experiencia subjetiva de ella, se acentúa cuando somos conscientes de que, también en el campo de la ciencia, se

(74) $\mathrm{E}_{\mathrm{n}}$ España han sido decisivos los trabajos de la «escuela» de Sanvisens, profesor de la Universidad $^{\mathrm{n}}$ de Barcelona y autor de seminales trabajos sobre pedagogía sistémico-cibernética, escuela seguida en varios discípulos suyos, profesores de teoría de la educación en diversas universidades españolas, sobre todo mediterráneas. Cfr.: Castillejo, J. L. y Colom, A. J. (1987). Pedagogía sistémica. Barcelona: Ceac.

(75) En la Universidad Complutense de Madrid existe, dentro de la Licenciatura en Pedagogía, una asignatura denominada «Pedagogía cognitiva» que se ofrece a los alumnos del último curso de los estudios.

(76) Colom, A. J. (2005). De la debilitat teórica de l'educado. Discurs de recepció com a membre numerari. Barcelona: Instituí d'Estudis Catalans. 
ha producido «el fin de las certidumbres». Pero, ya antes del nacimiento de la ciencia cognitiva, sabíamos con Heisenberg que, cuanto más sepamos 292 de una mitad del mundo, menos sabremos de la otra, y con Godel que una teoría no puede ser a un mismo tiempo completa y consistente $\left({ }^{77)}\right.$. Una teoría de la educación de impronta cognitiva es una teoría insegura. Pero con un apasionante programa de investigación por delante.

(77) Fernández-Rañada, A. (2002). Los científicos y Dios. Oviedo: Edics. Nobel, p. 340. 
Albar, E. y Quintanilla, M. A. (2002). Cultura tecnológica. Estudios de Ciencia, Tecnología y Sociedad. Barcelona: ICE de la UB - Horsori.

Asensio, J. M. (1997). Biología y educación. Barcelona: Ariel.

Asensio, J. M. (2000). La formación del docente en y para la complejidad. Teoría de la Educación, 12, pp. $29-43$.

Bechara, A., Damasio, H., Tranel, D., \& Damasio, A.R. (1997). Deciding advantageously before knowing the advantageous strategy. Science, 275, pp. 1293-1295.

Bereiter, C. (2002). Education and mind in the knowledge age. Mahwah, N. Lawrence Erlbaum Ass.

Bruner, J. S. (1969). On knowing. Essays for the left hand. N. York: Atheneum

Colom, A. J. (2002). La (de) const rue ción del conocimiento pedagógico. Nuevas perspectivas en teoría de la educación. Barcelona: Paidós.

Colom, A. J. (2005). De la débilitât teórica de Teducació. Diseurs de recepció com a membre numerari. Barcelona: Institut d'Estudis Catalans.

Consejo de la Unión Europea (2001). Futuros objetivos precisos de los sistemas de educación y formación. Bruselas: editor.

COTEC (1998). Redes neuronales. Madrid: editor.

Damasio, A. R. (1999). The feeling of what happens. Body and emotion in the making of consciousness. London: Harcourt Brace \& $\mathrm{Co}$.

Damasio, A.R. (1994). Descartes' error: Emotion, reason and the human brain. New York: Avon Books.

Educación y conocimiento (2002). Educação e conhecimento: um novo olhar. Revista Iberoamericana de Educación. Revista Iberoamericana de Educação, 30.

Educación y la formación (1995). Libro Blanco sobre la Enseñar y aprender. Hacia la sociedad cognitiva. Luxemburgo: Unión Europea.

Eisner, E. W. (1987). Procesos cognitivos y curriculum. Una base para decidir lo que hay que enseñar. Barcelona: Martínez Roca.

EURYDICE (2002). Compétences clés. Key competencies. Bruxelles: editor.

Gardner, H. (1985). The mind's new science. A history of the cognitive revolution. N. York: Basic Books.

Heidegger, M. (1972). ¿Qué significa pensar? Buenos Aires: Nova.

Informe Randstat (2004). Calidad del trabajo en la Europa de los Quince. La sociedad del conocimiento. Barcelona: ESADE.

Kackendoff, J.(1998). La consciencia y la mente computacional. Madrid: Visor.

Jeannerod, M. (1997). The cognitive neuroscience of action. London: Blackwell.

LeDoux, J.E. \& Phelps, E. A. (2000). Emotional networks in the brain. In M. Lewis \& J. Haviland-Jones (Eds.), Handbook of emotion (2nd ed.) (pp. 157-172). New York: Guilford. 
McClintock, R. 0., Streibel, M. J. y Vázquez, G. (1993). Comunicación, tecnología y diseños de instrucción: la construcción del conocimiento escolar y el uso de los ordenadores. Madrid: MEC-CIDE.

Mora, F. (Coord.) (2004). Esplendores y miserias del cerebro. Madrid: Fundación Santander Central Hispano.

Morin, E. (2001). Los siete saberes necesarios para la educación del futuro. Barcelona: Paidós.

Nyham, B. (Ed.) (2002). Taking steps towards the knowledge society. Reflections on the process of knowledge development. Luxembourg: CEDEFOP.

$\mathrm{OECD}$ (2001). What schools for the future. Paris: editor.

Scardamalia, M. (2002). Collective cognitive responsibility for the advancement of knowledge. In B. Smith (Ed.), Liberal education in a knowledge society (pp. 67-98). Chicago: Open Court.

Scardamalia, M. and Bereiter, C. (2003). Knowledge building. In Encyclopedia of education (2nd ed., pp. 1370-1373). New York: Macmillan Reference.

Vázquez, G. (1991). La pedagogía como ciencia cognitiva. Revista Española de Pedagogía, 49, 181, pp. 123-146.

Vázquez, G. (1993a). Inteligencia, tecnología y escuela en la sociedad post-industrial. En R. 0. McClintock, M. J. Streibel y G. Vázquez. Comunicación, tecnología y diseño de instrucción: la construcción del conocimiento escolar y el uso de los ordenadores (pp. 207-251). Madrid: M.E.C.-C.I.D.E.

Vázquez, G. (1993b). Problemas del conocimiento en la Edad Pos-industrial: ¿Qué debe enseñarse en la Escuela? En R. 0. McClintock, M. J. Streibel y G. Vázquez. Comunicación, tecnología y diseño de instrucción: la construcción del conocimiento escolar y el uso de los ordenadores (pp. 253-269). Madrid: M.E.C.-C.I.D.E.

Vázquez, G. (2002). El sistema educativo ante la educación de calidad para todos a lo largo $\mathrm{y}$ ancho de la vida. Revista de Educación (n ${ }^{\circ}$ extraordinario sobre Educación y Futuro), pp. 39-57.

Vázquez, G. (2003a). Aprender y pensar. Visión in(retro)spectiva del componente tecnológico-cognitivo del SITE. En P. Ortega (Ed.), Teoría de la Educación, ayer y hoy. Murcia: Selegráfica.

Vázquez, G. (2003b). Sociedad-red, ciudadanía cognitiva y educación. Revista de Educación (n ${ }^{\circ}$ extraordinario sobre Ciudadanía y Educación), pp. 13-31.

Vázquez, G. (2004). Desenvolvemento cognitivo e formación da competencia persoal dentro da familia. Revista Galega do Ensino, 44, pp. 19-48.

Vázquez, G. (Ed.) (1987). Educar para el siglo XXI. Criterios de valoración para el uso de la informática educativa. Madrid. FUNDESCO.

Vázquez, G. (Ed.) (1989). Los educadores y las máquinas de enseñar. Creencias y valoraciones ante la innovación tecnológica. Madrid. FUNDESCO.

Vázquez, G. (Ed.) (1991). Pedagogía cognitiva. Número monográfico. Revista Española de Pedagogía, 49, 191 .

Vázquez, G. y Bárcena, F. (1999). Pedagogía cognitiva: la educación y el estudio de la mente en la sociedad de la información. Teoría de la Educación. Educación y Cultura en la Sociedad de la Información, (1).

Wilson, R. A. y Keil, F. C. (Eds.) (2002). Enciclopedia MIT de las ciencias cognitivas. 2 vols. Madrid: Síntesis. 